\title{
Evaluation of Intraocular Lens Rotational Stability in a Multicenter Clinical Trial
}

\author{
John A Vukich (D' \\ Robert E Ang (D) ${ }^{2}$ \\ Benjamin JK Straker $\mathbb{D}^{3}$ \\ Devi Priya Janakiraman ${ }^{3}$ \\ Pamela J Smith ${ }^{3}$ \\ Juan F Batlle $\mathbb{D}^{4}$ \\ Kevin L Waltz' \\ 'Ophthalmic Research Consultants, \\ Indianapolis, IN, USA; ${ }^{2}$ Asian Eye \\ Institute, Makati City, Philippines; \\ ${ }^{3}$ Johnson \& Johnson Surgical Vision, Inc, \\ Santa Ana, CA, USA; ' ${ }^{4}$ aser Center, \\ Santo Domingo, Dominican Republic
}

Correspondence: Devi Priya Janakiraman Johnson \& Johnson Surgical Vision, I700 East St. Andrew Place, Santa Ana, CA 92705, USA

Tel + I 7|4-247-8429

Fax+7|4-247-8784

Email djanakil@its.jnj.com
Purpose: To evaluate the postoperative rotational stability of two prototype intraocular lens (IOL) designs (subsequently termed version 1 and version 2).

Patients and Methods: A prospective, multicenter, randomized, paired-eye, 6-month study evaluated the version 1 and version 2 IOLs. Results were compared with a control IOL (TECNIS $^{\circledR}$ toric 1-piece monofocal IOL) evaluated in a separate, similarly designed study. Participants aged $\geq 22$ years and scheduled to undergo bilateral cataract extraction were randomly assigned $1: 1$ to receive the version 1 or version 2 IOL in the first operative eye; the alternate test IOL was then implanted in the second operative eye.

Results: Mean absolute IOL rotation at postoperative week 1 was the primary effectiveness end point. Additional end points included the percentage of eyes with postoperative IOL rotation $>5^{\circ}>10^{\circ}$, direction of lens rotation, surgeon-reported ease of IOL handling during implantation, and safety. At postoperative week 1 , mean ( \pm standard deviation) absolute IOL rotation was significantly lower for both version 1 and version 2 versus control $\left(0.88^{\circ}\right.$ [ \pm 0.94$]$ and $0.71^{\circ}[ \pm 0.69]$ vs $2.24^{\circ}[ \pm 3.21]$, respectively; both $\left.P<0.001\right)$. For both study lenses, absolute rotation was $<5^{\circ}$ for all eyes at postoperative week 1 , and no cases of rotation $>10^{\circ}$ were observed at any postoperative time point. From postoperative week 1 onward, version 2 had a statistically significant clockwise bias in the direction of rotation $(P=0.03)$; similar findings were observed for version 1. Surgeons reported acceptable ease of IOL handling during implantation for both version 1 and version 2 . No device-related adverse events were reported.

Conclusion: Both the version 1 and version 2 IOLs, each with frosted, squared haptics, demonstrated improved postoperative rotational stability compared with a control lens without frosted haptics. Because version 2 had the same overall geometry as the current TECNIS toric IOL, this design was selected for commercialization.

Trial Registration: German Clinical Trials Register, DRKS00015287.

Keywords: astigmatism, cataract, IOL rotation, surgery, toric IOL

\section{Introduction}

In eyes with corneal toricity, toric intraocular lenses (IOLs) reduce postoperative astigmatism after cataract surgery, improving uncorrected distance visual acuity and providing greater spectacle independence, compared with non-toric IOLs. ${ }^{1}$ Correct postoperative positioning and stabilization of toric lenses are critical factors in achieving optimal astigmatism correction; each $10^{\circ}$ of misalignment from postoperative rotation increases residual astigmatism by approximately one-third of the correcting cylinder power. ${ }^{2} \mathrm{~A}$ deviation of $\geq 5^{\circ}$ may be clinically relevant, and a deviation of $\geq 10^{\circ}$ may be an indication for secondary surgical intervention. ${ }^{3,4}$ 
The TECNIS Toric 1-Piece (Johnson \& Johnson Vision, Santa Ana, CA, USA) monofocal IOL is an ultraviolet lightabsorbing posterior chamber IOL that compensates for corneal spherical aberrations and corneal astigmatism. ${ }^{5}$ Previous studies investigating the rotational stability of this 1-piece toric IOL have reported postoperative rotation in some participants. ${ }^{6-8}$ Research suggests that in cases of IOL rotation, most misalignment occurs within the first hour after surgery. ${ }^{8}$ In a retrospective review of toric IOL rotation data collected from a toric back-calculation website, the estimated overall rate of postoperative rotation $\geq 5^{\circ}$ for the TECNIS toric IOL was low $(<2 \%)$ but higher than that for the AcrySof toric IOL; the TECNIS toric IOL was also found to be biased toward counterclockwise rotation. ${ }^{6}$ Another retrospective cohort study also reported a tendency for the TECNIS toric IOL to rotate in a counterclockwise direction, with higher postoperative mean absolute rotation $\left(3.79^{\circ}\right.$ vs $\left.2.72^{\circ}\right)$ and fewer cases of small rotation (percentage of eyes with $\leq 5^{\circ}$ rotation, $81.8 \%$ vs $91.9 \%$; $\leq 10^{\circ}$ rotation, $93.2 \%$ vs $97.8 \%$ ), compared with the AcrySof toric IOL. ${ }^{7}$ However, no significant difference was found in refractive outcomes (postoperative manifest refraction cylinder) or corrected visual acuity between these lenses. ${ }^{7}$

To address the issue of postoperative rotation, several prototype IOLs were developed that featured modified haptic designs with the goal of reducing the occurrence of large IOL rotations following implantation. A new clinical method was developed whereby the participants' eyes were photographed with the IOL in its final position immediately before discharge from the operating theater and were subsequently photographed at the day 1 , week 1 , month 1 , and month 6 postoperative visits. ${ }^{9}$ With custom-image processing software, the relative difference in orientation of the IOL (ie, the amount of lens rotation) was determined between operative and postoperative time points. ${ }^{9}$

The objective of the present 6-month study was to evaluate the postoperative rotational stability of two prototype IOLs with modified haptic designs (hereafter referred to as version 1 and version 2) and to compare the stability of a control IOL, which featured the same haptic design as the TECNIS toric (ZCT series) lens collected from a separate study with a similar study design.

\section{Patients and Methods}

\section{Study Design}

This 6-month, randomized, paired-eye, multicenter study (German Clinical Trials Register, DRKS00015287) was conducted at three study sites in Asia Pacific (Asian Eye Institute, Manila, Philippines) and Latin America (Laser Center, Santo Domingo, Dominican Republic; Centro de Oftalmología y Cirugía Plástica, San Salvador, El Salvador). All participants were examined through 6 months after surgery, with a minimum of nine study visits: preoperative examination of both eyes, operative visit for the first eye, day 1 and week 1 postoperative examinations after the first eye surgery, operative visit for the second eye (after the day 1 postoperative examination of the first eye but no more than 30 days after the first eye surgery), day 1 and week 1 postoperative examinations after the second eye surgery, and month 1 and month 6 postoperative examinations of both eyes. All participants provided written informed consent, and each local institutional review board approved the study, which was conducted in accordance with the Declaration of Helsinki.

Rotation data for both IOL versions in this study were compared with rotation data for a control IOL from a separate clinical study that was conducted at the same three study sites and at four additional sites using a similar study protocol and the same methods for measuring rotational stability.

\section{Inclusion and Exclusion Criteria}

Participants were included in the study if they were aged 22 years or older; were scheduled to undergo bilateral cataract extraction and implantation of posterior chamber monofocal IOLs between +10.0 and +25.0 diopters; were candidates for achieving postoperative best-corrected distance visual acuity of 20/30 Snellen or better; had clear intraocular media (other than cataract) in each eye; were available and willing to comply with the study procedures; had not participated in any other clinical trial within 30 days before the preoperative visit; and provided signed informed consent.

Key exclusion criteria that applied to each eye included pupil abnormalities, recent ocular trauma or surgery, previous refractive surgery, increased risk for zonular rupture, poorly controlled diabetes, or other ocular or systemic disease that might have confounded study outcomes.

\section{Randomization}

Participants were randomly assigned in a 1:1 ratio to receive either the version 1 or the version 2 test IOL in the first operative eye; the alternate IOL was then implanted in the contralateral eye. The randomization schedule was uploaded into the system by the study sponsor and was made visible only to site personnel on an incremental basis as participants were randomly assigned. 
Each participant was assigned a lens sequence per the randomization schedule within the electronic data capture system after signing the informed consent form and after meeting all eligibility criteria; the investigator documented which eye was to be implanted first based on their standard clinical practice (ie, the eye with the worse cataract, poorer best-corrected distance vision, and/or more severe optical/ visual manifestations). The randomization schedule was generated using SAS (SAS Institute, Cary, NC) with a block size of 6 ( 2 investigational lenses $\times 3$ implantation orientations) and with lens assignments balanced within each block. The randomization schedule defined which lens was to be implanted in the first eye, with the alternate lens implanted in the fellow eye. Lens orientation was also randomized at one of three orientations, where the surgeon was to align the lens axis markings (horizontal, vertical, or oblique); lens orientation was the same for both eyes of each participant. Participants and surgeons were not masked to the lens assignment. However, photo-analysts were masked to the identity of the study lenses.

\section{Study Intraocular Lens Description}

Both test lenses were prototype 1-piece IOLs designed to minimize the occurrence of large IOL rotations after implantation. Both had the same overall characteristics as the TECNIS Toric 1-Piece IOLs (ZCT series) except that they featured standard monofocal (ie, non-astigmatic) optics primarily to enable faster rates of enrollment and modified haptic designs (Figure 1A). Key design differences between the version 1 design and the TECNIS toric design were that version 1 had frosted haptics and a modified haptic geometry with a slightly larger overall lens diameter. The key design difference between the version 2 design and the TECNIS toric design was that the haptics for version 2 were frosted; however, the overall lens geometry, diameter, and haptic shape were otherwise the same as those of the TECNIS toric design. The only design difference between the control lens and the TECNIS toric lens was that the control featured a non-astigmatic monofocal optic. To enable measurement of lens rotation, all test and control lenses featured four orientation markings adjacent to each haptic-optic junction (as in the TECNIS toric design). Furthermore, in the control study, all study participants had standard monofocal (ie, non-astigmatic) IOLs implanted in both eyes. However, results of only the control lens (one eye of each participant) were referenced for the purpose of this publication.

\section{Surgical Technique}

Immediately before surgery, the investigator marked the sclera according to standard procedure for a toric lens case. For each eye, investigators used their preferred corneal marking technique to mark the horizontal $\left(180^{\circ}\right)$, oblique $\left(45^{\circ}\right)$, or vertical $\left(90^{\circ}\right)$ axis based on the randomization scheme to enable alignment between intended orientation and actual IOL orientation during surgery.

The surgical technique for cataract extraction and IOL implantation was identical for test and control IOLs. Surgeons used their standard, small-incision surgical technique for cataract extraction, which might have included phacoemulsification/aspiration alone or laser fragmentation combined with phacoemulsification/aspiration. IOLs were folded for implantation and inserted into the capsular bag using the UNFOLDER Platinum 1 Series Implantation System (Johnson \& Johnson Vision). Following lens insertion into the capsular bag, the lens was rotated/positioned to precisely align the lens fiducial marks with the intended orientation using the axis fiducial marks at each of the haptic-optic junctions of the IOL. Once the IOL was positioned appropriately with the eye at normal tension, all viscoelastic around the IOL was removed, the incision was hydrated, and a scleral bounce test -with the surgeon repeatedly pressing on the sclera at the approximate location of the haptics with a Weck-Cel (BVI, Waltham, MA, USA) or similar surgical instrument and estimating the resultant lens rotation - was performed. If the estimated lens rotation was $>5^{\circ}$, the lens was repositioned, but if the rotation resulting from the scleral bounce test was estimated to be $\leq 5^{\circ}$, repositioning was at the discretion of the surgeon. In the separate study that investigated the control IOL, all surgical procedures were identical to those described above, including the scleral bounce test and repositioning criteria.

After each surgical case, surgeons completed a questionnaire regarding the ease of IOL handling during implantation using their standard preoperative, operative, intraoperative, and postoperative medication regimens for each eye.

\section{Analysis of Photographs}

Figure 1B provides a photographic comparison of frosted haptics, as featured in both test IOLs (version 1 and version 2), and unfrosted haptics, as featured in the control IOL.

At the end of each surgery (regardless of whether repositioning was required), $\geq 3$ digital photographs were taken of the eye through the surgical microscope with the 
A

\begin{tabular}{|l|l|l|l|}
\hline & Version 1 & Version 2 & $\begin{array}{c}\text { Control } \\
\text { (Current Toric Platform) }\end{array}$ \\
\hline Platform design feature & $\begin{array}{l}\text { - Haptics modified in shape and } \\
\text { frosted }\end{array}$ & $\begin{array}{l}\text { - Same as current 1-piece } \\
\text { platform with frosted } \\
\text { haptics }\end{array}$ & $\begin{array}{l}\text { - Current 1-piece platform } \\
\text { with unfrosted haptics }\end{array}$ \\
\hline Lens drawing & & \\
\hline Overall diameter & $13.5 \mathrm{~mm}$ & \\
\hline
\end{tabular}

B
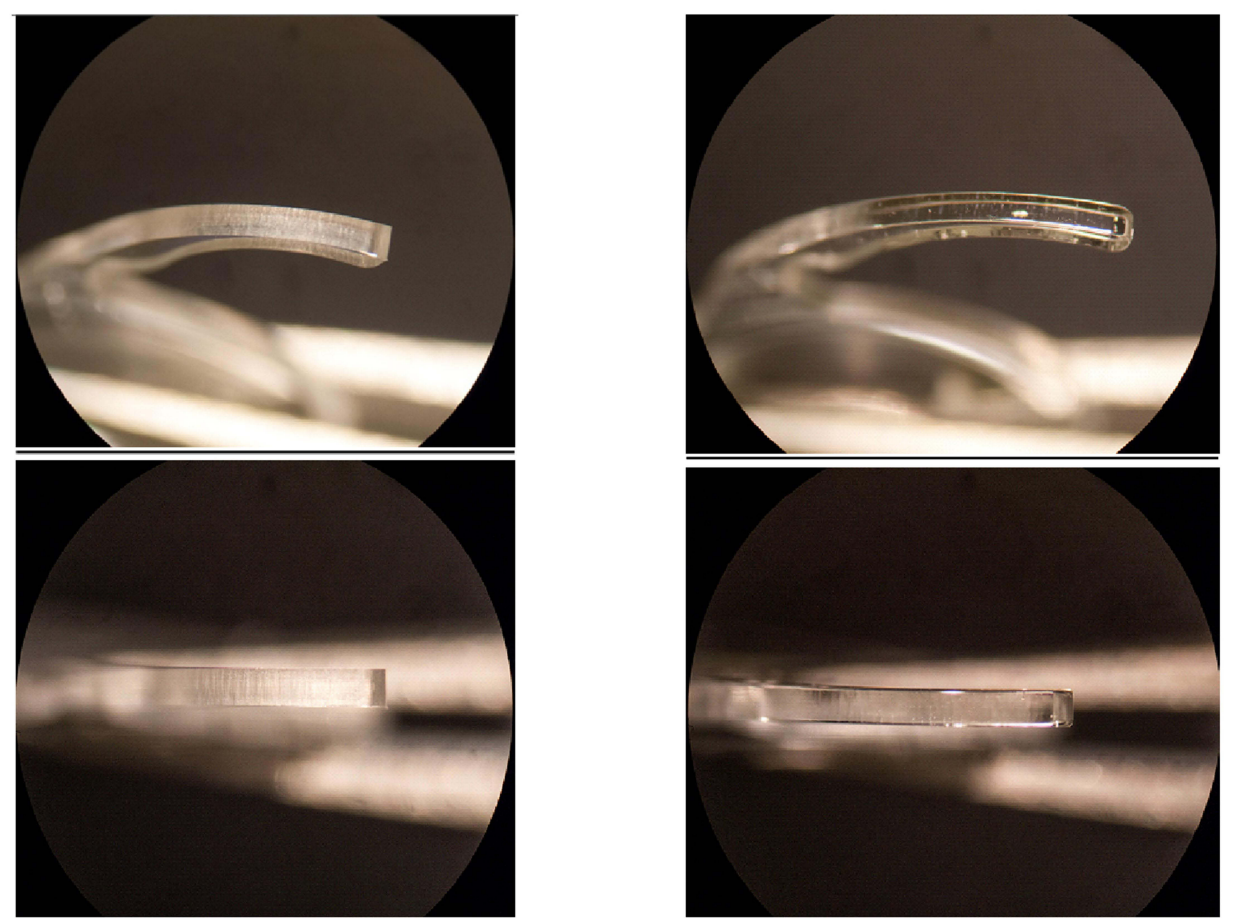

Figure I Design and characteristic features of the version I and version 2 test IOLs and the control IOL (A) and photographic comparison of frosted (left) and unfrosted (right) haptics at high magnification (B).

Abbreviation: IOL, intraocular lens.

lens in its final position. Similarly, $\geq 3$ postoperative photographs were taken at 1 day, 1 week, 1 month, and 6 months after IOL implantation using a digital camera attached to a slit lamp biomicroscope. Care was taken to ensure clear visibility in all photographs of the limbal and scleral vessels and the lens axis markings.
Paired operative and postoperative study photographs were analyzed by two independent photo-analysts masked to the origins of the photographs and trained to review and analyze photographs using custom image processing software in MATLAB (MathWorks, Natick, MA, USA). At each operative and postoperative time point, each analyst 
selected the best image of the three photographs captured for each eye. To enhance image contrast and detail visibility, a Retinex filter was applied. Corresponding ocular landmarks were then identified in paired operative and postoperative images to register them with respect to ocular orientation. Subsequently, the IOL orientation was identified in each image by selecting and fitting a line through the IOL markings, and the signed lens rotation was calculated as the difference in orientation between the operative and postoperative images. A detailed description of the analysis software, including results of a validation protocol, has been published. ${ }^{9}$ Photographs were reviewed and excluded from analysis if the orientation of the IOL could not be accurately determined (ie, due to insufficient pupil dilation resulting in the iris obscuring the IOL orientation marks). Data from both analysts were combined by averaging the signed rotation values from each analyst on a case-by-case basis. If the analysts had poor agreement, specifically if the signed rotation value from analyst $A$ was not within $\pm 3^{\circ}$ of the signed rotation value from analyst $B$, both analysts repeated the analysis of that case. Cases were excluded (from photographic analysis only) if agreement to within $\pm 3^{\circ}$ could not be achieved after a second round of analysis. The methods described for photographic analysis were identical to those used in the study that investigated the control IOL.

\section{End Points}

The primary effectiveness end point was the mean absolute IOL rotation at the week 1 postoperative time point. This was compared with the mean absolute rotation of the control IOL at 1 week. Success was established if either of the test IOLs demonstrated a statistically significant reduction in mean absolute rotation compared with the control IOL at the week 1 postoperative time point.

Additional study end points included the following: percentage of eyes with $\mathrm{IOL}$ rotation $>5^{\circ}$ and $>10^{\circ}$ (relative to operative placement) at each postoperative visit; direction of lens rotation; safety as measured by complications, adverse event (AE), and serious $\mathrm{AE}$ (SAE) rates; and surgeon responses to an operative questionnaire regarding the ease of IOL handling and implantation.

\section{Statistical Analysis}

Study sample size assumptions were based on the results of previous IOL rotational stability studies. Assuming a 1-sided alpha level of 0.05 , a standard deviation (SD) of 3.5 for the
MER000 (control) IOL and 2.1 for the investigational (test) IOLs, and a sample size of 135 participants in each IOL group, the study was estimated to have $88 \%$ power to detect a mean difference in absolute IOL rotation between either of the test IOLs and the control IOL of $\geq 1^{\circ}$. As a result, enrollment of approximately 193 participants was required to have a group of 135 contralateral implantation participants, taking into account a dropout/screen failure rate of $30 \%$. However, enrollment for this study was stopped early, before that number of contralateral implantation participants could be reached because the SD values were lower than originally estimated, enabling the detection of a given effect size with fewer participants.

All analyses were performed on all participants in whom the study lens was implanted and who had data available (ie, no data were imputed). If a participant discontinued early, any data available before study exit were included.

Comparison of the test IOLs with the control IOL for mean absolute lens rotation was performed using a 1-sided, 2-sample $t$ test (Satterthwaite $t$ test). The 2-sided Fisher's exact test was used to compare IOL groups for the proportion of eyes with absolute lens rotation $>5^{\circ}$. A 2-sided, 1-sample $t$ test comparing the mean to 0 (no directional shift) was used to evaluate mean signed rotation. Simple linear regression was used to evaluate the effects of axial length on absolute lens rotation. Summary statistics were calculated for absolute lens rotation, including the mean, SD, median, minimum, maximum, and $95 \%$ confidence interval. The frequency and proportion of eyes with medical findings/lens findings/complications/AEs and operative questionnaire data were also reported by IOL.

\section{Results}

\section{Disposition and Baseline Characteristics}

The first surgery was performed on October 16, 2018, and the last participant's final surgery was performed on April 26, 2019; the final follow-up visit for the last participants was on September 21, 2019. In total, 99 eyes were implanted with version 1 and 98 eyes with version 2 . The first eye of one participant was implanted with the version 1 lens, but the second eye was implanted with a nonstudy lens due to a surgical complication. Data for the control lens included 124 eyes implanted with the control IOL.

Demographic and baseline characteristics of the participants with the version 1, version 2, and control IOLs were generally similar (Table 1). Mean (SD) ages for the version 1, version 2, and control groups were 67.5 (8.7), 67.3 (8.7), and 
Table I Participant Demographics at Baseline

\begin{tabular}{|c|c|c|c|}
\hline & Version I & Version 2 & Control \\
\hline & $N=99$ & $N=98$ & $N=124$ \\
\hline \multicolumn{4}{|l|}{ Age, years } \\
\hline Mean (SD) & $67.5(8.7)$ & $67.3(8.7)$ & $66.5(8.2)$ \\
\hline \multicolumn{4}{|l|}{ Age group, n (\%) } \\
\hline$<60$ years & $15(15.2)$ & $15(15.3)$ & $24(19.4)$ \\
\hline $60-69$ years & $43(43.4)$ & $43(43.9)$ & $59(47.6)$ \\
\hline $70-79$ years & $35(35.4)$ & $35(35.7)$ & $34(27.4)$ \\
\hline$\geq 80$ years & $6(6.1)$ & $5(5.1)$ & $7(5.6)$ \\
\hline \multicolumn{4}{|l|}{ Sex, n (\%) } \\
\hline Female & $68(68.7)$ & $68(69.4)$ & $87(70.2)$ \\
\hline Male & 31 (3I.3) & $30(30.6)$ & $37(29.8)$ \\
\hline \multicolumn{4}{|l|}{ Race, n (\%) } \\
\hline Asian & $43(43.4)$ & $43(43.9)$ & $57(46.0)$ \\
\hline Black & $3(3.0)$ & $3(3.1)$ & I $(0.8)$ \\
\hline White & $\mathrm{I}(\mathrm{I} .0)$ & I (I.0) & $22(17.7)$ \\
\hline Other & $52(52.5)$ & $5 \mathrm{I}(52.0)$ & $44(35.5)$ \\
\hline \multicolumn{4}{|l|}{ Ethnicity, n (\%) } \\
\hline Hispanic/Latino & $57(57.6)$ & $56(57.1)$ & $49(39.5)$ \\
\hline Not Hispanic/Latino & $42(42.4)$ & $42(42.9)$ & $75(60.5)$ \\
\hline \multicolumn{4}{|l|}{ Iris color, n (\%) } \\
\hline Brown/black & $98(99.0)$ & $97(99.0)$ & $105(84.7)$ \\
\hline Blue/gray & I (I.0) & I (I.0) & $15(12.1)$ \\
\hline Green/hazel & 0 & 0 & $4(3.2)$ \\
\hline \multicolumn{4}{|l|}{ Axial length, mm } \\
\hline Mean & 23.29 & 23.33 & 23.42 \\
\hline SD & 0.92 & 0.92 & 0.93 \\
\hline Median & 23.14 & 23.21 & 23.33 \\
\hline Min & 21.65 & 21.75 & 21.76 \\
\hline Max & 26.01 & 25.93 & 26.41 \\
\hline
\end{tabular}

Notes: Max, maximum; Min, minimum.

66.5 (8.2) years, respectively. In the version 1, version 2, and control groups, most participants were female (68.7\%, $69.4 \%$, and $70.2 \%$, respectively) and most were classified as "other race" $(52.5 \%, 52.0 \%$, and $35.5 \%$, respectively) or Asian (43.4\%, 43.9\%, and 46.0\%, respectively).

\section{Photograph Analysis}

Overall, 94\% (93/99), 93\% (91/98), and 94\% (117/124) of participants with the version 1, version 2, and control IOLs were included in the rotational analysis at postoperative week 1 (Table 2). To estimate the repeatability of the photographic method, a Bland-Altman plot was generated showing the average of the month 1 and month 6 signed orientation versus the difference between these two time points for each eye
(Figure 2). When data for both test lenses and the control were combined, a total of 274 eyes with signed rotation data at both month 1 and month 6 visits were included in this plot. The mean difference between time points was $-0.21^{\circ}(0.93)$, with upper and lower $95 \%$ limits of agreement of $+1.62^{\circ}$ and $2.04^{\circ}$, respectively. At postoperative month 6, 93\% (92/99), $88 \%(86 / 98)$, and $83 \%(103 / 124)$ of participants with the version 1 , version 2 , and control IOLs were included in the rotational analysis. Among the reasons for the exclusion of eyes from analysis were that images could not be analyzed because of insufficient pupil dilation or other image quality issues, the participant discontinued from the study, and analyst results were not in agreement to within $3^{\circ}$ after repeated analysis.

\section{Absolute Lens Rotation}

Summary statistics for mean absolute IOL rotation at each postoperative time point are presented in Table 3. Boxplots of absolute lens rotation from operative to postoperative week 1, month 1, and month 6 are shown in Figure 3. At postoperative week 1 , mean absolute IOL rotation was $0.71^{\circ}( \pm 0.69)$ for the version $2 \mathrm{IOL}$ and $2.24^{\circ}( \pm 3.21)$ for the control IOL, resulting in a statistically significant difference of $-1.53(P<0.001)$ (Table 3; Figure 3A). Similar findings were observed for the version 1 IOL, with a mean absolute IOL rotation of $0.88^{\circ}( \pm 0.94)$ that was significantly smaller than that of the control at 1 week (difference $-1.37 ; P<0.001$ ) (Table 4; Figure 3A).

Mean absolute rotations at postoperative month 1 and month 6 were $0.99^{\circ}( \pm 0.95)$ and $1.08^{\circ}( \pm 0.97)$ for the version $1 \mathrm{IOL}, 0.87^{\circ}( \pm 0.92)$ and $1.03^{\circ}( \pm 1.09)$ for the version $2 \mathrm{IOL}$, and $2.47^{\circ}( \pm 3.31)$ and $2.53^{\circ}( \pm 3.27)$ for the control IOL (Table 3; Table 4; Figure 3B and C). Differences in mean absolute rotation between the test IOLs and control remained statistically significant for both version 1 and version 2 at the month 1 and month 6 postoperative time points (all $P<0.001$ ).

Comparing version 1 against version 2, the mean absolute IOL rotation was consistently lower for version 2 at all postoperative time points; however, this difference was not statistically significant at any time point (all $P>0.05$ ) (Table 5).

\section{Frequency of Large Rotations}

For the version 2 test IOL, absolute rotation was $>5^{\circ}$ in zero eyes at postoperative day 1 and week 1 , one $(1.2 \%)$ eye at postoperative month 1 , and one (1.2\%) eye at postoperative month 6 . Similarly, for the version 1 test IOL, 


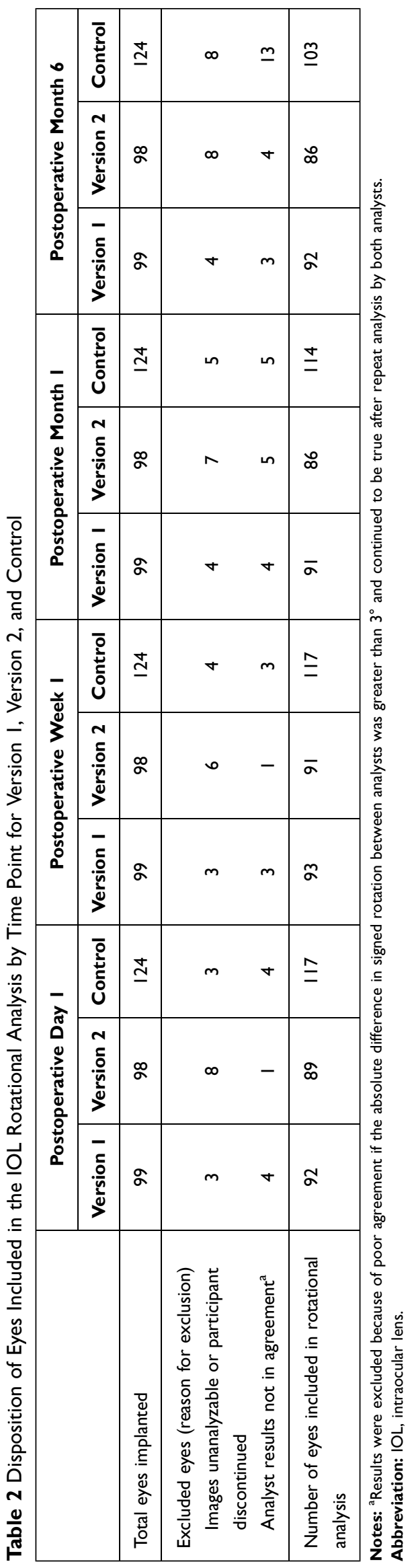

absolute rotation $>5^{\circ}$ was reported in zero eyes at postoperative day 1 and week 1 , one (1.1\%) eye at postoperative month 1, and no eyes at postoperative month 6 . For both version 1 and version 2 IOLs, no cases of rotation $>10^{\circ}$ were observed through 6 months. In the control group, absolute IOL rotation $>5^{\circ}$ and $>10^{\circ}$ was reported in $12(10.3 \%)$ and five $(4.3 \%)$ eyes at postoperative week $1,13(11.4 \%)$ and five $(4.4 \%)$ eyes at postoperative month 1 , and $11(10.7 \%)$ and five $(4.9 \%)$ eyes at postoperative month 6 , respectively.

At postoperative week 1, the proportion of cases with absolute IOL rotation $>5^{\circ}$ was significantly lower for both version 1 and version 2 relative to control (Fisher's exact test, both $P=0.001$ ). This statistical significance was maintained at postoperative month 1 (both $P=0.004$ ) and month 6 $(P=0.007$ for version $2, P=0.001$ for version 1$)$.

\section{Direction of IOL Rotation}

For both test and control IOLs, analysis of the mean signed lens orientation suggested a small but significant clockwise drift in orientation over time (ie, increasingly negative mean signed rotation from operative) (Figure 4). This clockwise bias in rotation direction was significant for the version 2 IOL at postoperative week 1 (1-sample $t$ test, $P=0.03$ ) and for all IOLs at postoperative month 1 ( $P=0.001$ for version 1, $P=0.006$ for version 2, $P=0.02$ for control IOLs) and at postoperative month $6(P<0.001$ for version 1 and version 2, $P=0.007$ for control IOLs). Although statistically significant, the magnitude of this drift was small for both groups (the maximum mean signed rotation was $1.1^{\circ}$ for control at 6 months), suggesting that this bias in rotation direction was not clinically significant.

\section{Correlation of Signed Rotation Between Postoperative Time Points}

For version 1, version 2, and control IOLs, the signed IOL rotation on postoperative day 1 was highly correlated to the signed rotation at future postoperative time points (Figure 5A-C), suggesting that most lens rotation occurred before the day 1 postoperative visit.

\section{Relationship Between IOL Rotation and Axial Length}

Figure 6 depicts a scatterplot of absolute IOL rotation at 1 week compared with axial length at baseline for the version 1, version 2, and control IOLs. Linear regression analysis indicated a trend of increasing IOL rotation with 


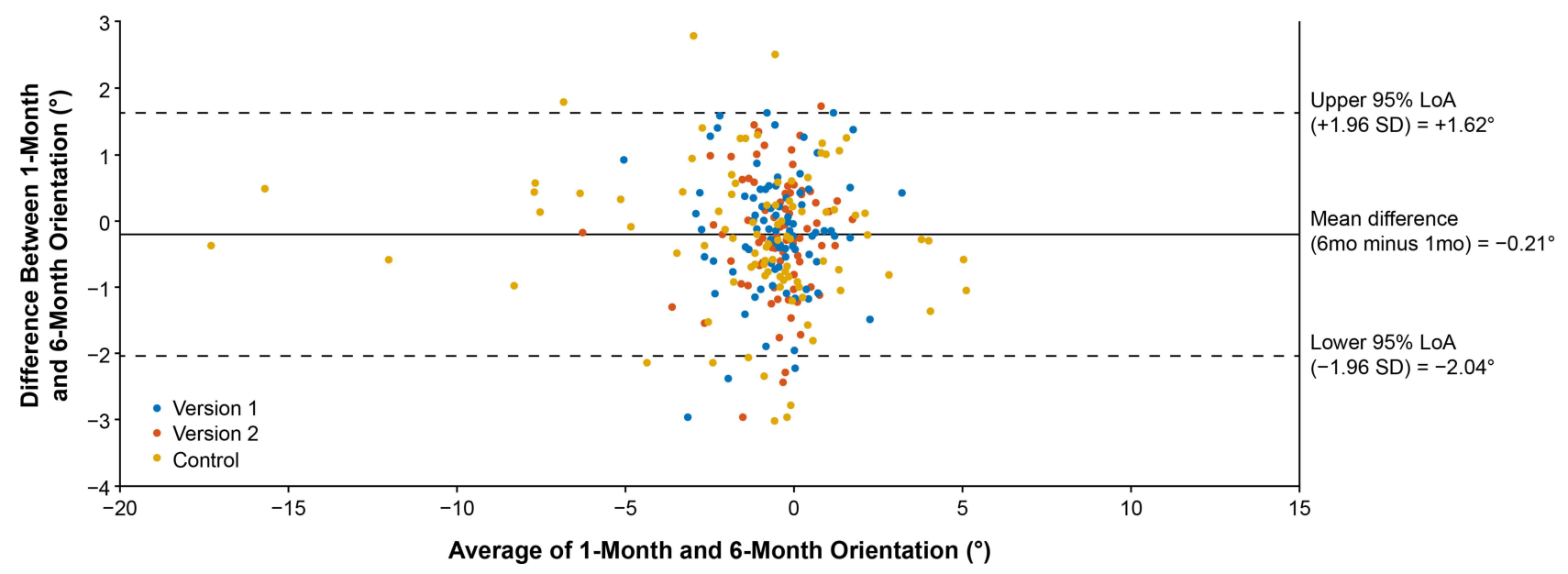

Figure 2 Bland-Altman plot showing the average of month I and month 6 signed orientation versus difference between these time points (month 6 minus month I orientation), by IOL. Mean difference and $95 \%$ limits of agreement are shown for test and control IOLs combined. Negative values indicate a clockwise difference in orientation between month I and month 6 time points.

Abbreviations: IOL, intraocular lens; LoA, limit of agreement.

greater axial length for the control design; however, this was not statistically significant $\left(\mathrm{R}^{2}=0.01 ; P=0.26\right)$. Additionally, no statistically significant relationship between axial length and absolute IOL rotation at 1 week was found for either the version $1\left(\mathrm{R}^{2}=0.003 ; P=0.60\right)$ or version $2\left(\mathrm{R}^{2}=0.002 ; P=0.67\right)$ IOLs. Similar results were observed at postoperative month 1 and month 6 .

\section{Serious and Device-Related Adverse Events}

Three SAEs were reported in participants with the version 2 IOL. Two of these were ocular SAEs (diabetic macular edema and hemicentral retinal vein occlusion). The third SAE was nonocular: the participant died of an unknown cause before the postoperative month 1 visit. None of the SAEs were deemed related to the device, and no nonserious device-related AEs were reported for either the version 1 or version 2 IOLs.

\section{Surgeon Assessment of Ease of IOL Handling During Implantation}

Surgeon responses to the operative questionnaire for the version $1(\mathrm{n}=99)$, version $2(\mathrm{n}=98)$, and control IOL $(\mathrm{n}=124)$ groups are summarized in Figure $7 \mathrm{~A}-\mathrm{E}$. The

Table 3 Comparisons of Mean Absolute IOL Rotations for Version 2 versus Control at Postoperative Day I, Week I, Month I, and Month 6

\begin{tabular}{|c|c|c|c|c|c|c|c|c|c|c|}
\hline $\begin{array}{l}\text { Postoperative Time } \\
\text { Point }\end{array}$ & IOL & $\mathbf{N}$ & $\begin{array}{c}\text { Mean } \\
\text { Degrees }\end{array}$ & SD & Median & Min & Max & $\begin{array}{l}\text { Lower } \\
95 \% \mathrm{Cl}\end{array}$ & $\begin{array}{l}\text { Upper } \\
95 \% \mathrm{Cl}\end{array}$ & $P$ \\
\hline \multirow[t]{3}{*}{ Day I } & Version 2 & 89 & 0.727 & 0.753 & 0.448 & 0.001 & 3.298 & 0.568 & 0.885 & - \\
\hline & Control & 117 & 2.393 & 3.051 & 1.424 & 0.007 & 15.159 & 1.835 & 2.952 & - \\
\hline & Difference & - & -1.667 & - & - & - & - & -2.247 & -1.087 & $<0.001$ \\
\hline \multirow[t]{3}{*}{ Week I } & Version 2 & 91 & 0.713 & 0.690 & 0.460 & 0.006 & 2.742 & 0.569 & 0.856 & - \\
\hline & Control & 117 & 2.243 & 3.211 & 1.032 & 0.017 & 16.800 & 1.655 & 2.831 & - \\
\hline & Difference & - & -1.530 & - & - & - & - & -2.135 & -0.926 & $<0.001$ \\
\hline \multirow[t]{3}{*}{ Month I } & Version 2 & 86 & 0.871 & 0.915 & 0.537 & 0.010 & 6.166 & 0.675 & 1.067 & - \\
\hline & Control & 114 & 2.466 & 3.311 & 1.296 & 0.026 & 17.093 & $\mathrm{I} .85 \mathrm{I}$ & 3.080 & - \\
\hline & Difference & - & -1.595 & - & - & - & - & -2.238 & -0.951 & $<0.001$ \\
\hline \multirow[t]{3}{*}{ Month 6} & Version 2 & 86 & 1.031 & 1.094 & 0.692 & 0.027 & 6.354 & 0.796 & 1.266 & - \\
\hline & Control & 103 & 2.533 & 3.267 & 1.460 & 0.001 & 17.472 & 1.894 & 3.171 & - \\
\hline & Difference & - & -1.502 & - & - & - & - & -2.180 & -0.824 & $<0.001$ \\
\hline
\end{tabular}

Abbreviations: IOL, intraocular lens; Max, maximum; Min, minimum. 

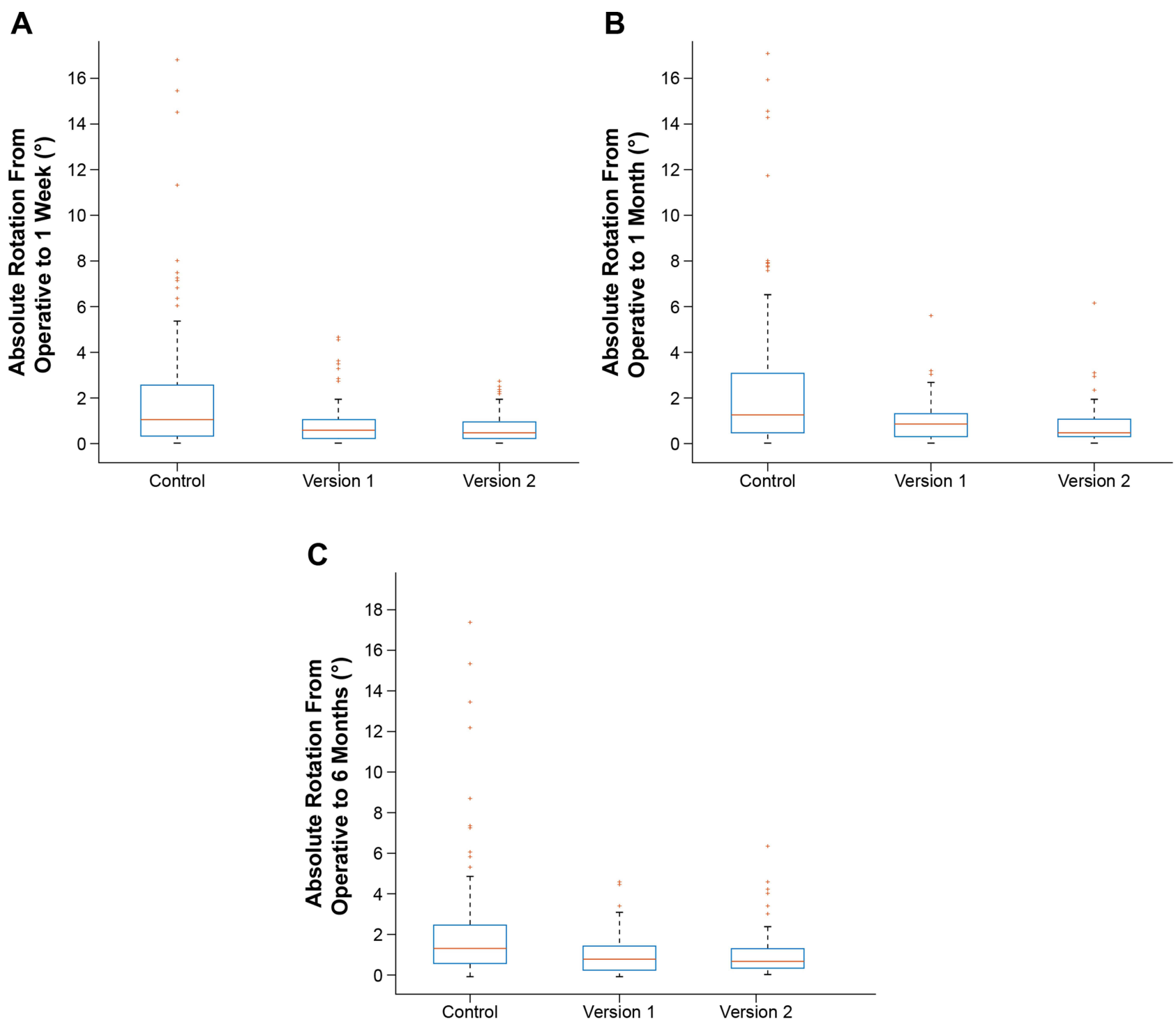

Figure 3 Boxplot of absolute IOL rotation from operative to postoperative week I (A), postoperative month I (B), and postoperative month 6 (C). Abbreviation: IOL, intraocular lens.

distribution of responses to the questions was generally similar between all three IOLs. For all questions, at least $79 \%$ of surgeon responses were either 4 or 5 for both the version 1 and version 2 lenses on a response scale from 1 (very difficult) to 5 (very easy). Compared with the control design, surgeon responses for the version 2 IOL suggested that there was a slight increase in lens resistance to rotation within the capsule for clockwise and counterclockwise rotations during implantation (Figure 7B and $\mathrm{C}$ ), whereas the response distributions for version 1 were more similar to those of the control IOL for these questions. In response to the item "removal of viscoelastic from behind the IOL," both version 1 and version 2 lenses were rated 4 or 5 in most cases (Figure 7D). Removal of viscoelastic was reported to impact the lens position in fewer cases for the test IOLs ("yes" response in $10 \%$ of cases for both) compared with the control IOL ("yes" response in $15 \%$ of cases) (Figure 7E).

\section{Discussion}

IOL rotation data collected using a photographic test method in this study indicated a significant improvement in rotational stability for both version 1 and version 2 lenses compared with a control lens. For both test lenses, a modified haptic manufacturing process resulted in the haptics being frosted, whereas for the control lens, the haptic surface and shape were identical to those of the 
Table 4 Comparisons of Mean Absolute IOL Rotations for Version I versus Control at Postoperative Day I, Week I, Month I, and Month 6

\begin{tabular}{|c|c|c|c|c|c|c|c|c|c|c|}
\hline $\begin{array}{l}\text { Postoperative Time } \\
\text { Point }\end{array}$ & IOL & $\mathbf{N}$ & $\begin{array}{c}\text { Mean } \\
\text { Degrees }\end{array}$ & SD & Median & Min & Max & $\begin{array}{l}\text { Lower } \\
95 \% \mathrm{Cl}\end{array}$ & $\begin{array}{l}\text { Upper } \\
95 \% \mathrm{Cl}\end{array}$ & $P$ \\
\hline \multirow[t]{3}{*}{ Day I } & Version I & 92 & $0.84 I$ & 0.994 & 0.517 & 0.012 & 4.745 & 0.636 & 1.047 & - \\
\hline & Control & 117 & 2.393 & 3.051 & 1.424 & 0.007 & 15.159 & 1.835 & 2.952 & - \\
\hline & Difference & - & -1.552 & - & - & - & - & -2.146 & -0.958 & $<0.001$ \\
\hline \multirow[t]{3}{*}{ Week I } & Version I & 93 & 0.877 & 0.939 & 0.654 & 0.016 & 4.719 & 0.684 & 1.070 & - \\
\hline & Control & 117 & 2.243 & 3.211 & 1.032 & 0.017 & 16.800 & 1.655 & 2.831 & - \\
\hline & Difference & - & -1.366 & - & - & - & - & -1.984 & -0.748 & $<0.001$ \\
\hline \multirow[t]{3}{*}{ Month I } & Version I & 91 & 0.989 & 0.953 & 0.791 & 0.004 & 5.517 & 0.790 & 1.187 & - \\
\hline & Control & 114 & 2.466 & 3.311 & 1.296 & 0.026 & 17.093 & $1.85 \mathrm{I}$ & 3.080 & - \\
\hline & Difference & - & -1.477 & - & - & - & - & -2.121 & -0.833 & $<0.001$ \\
\hline \multirow[t]{3}{*}{ Month 6} & Version I & 92 & 1.079 & 0.972 & 0.821 & 0.023 & 4.633 & 0.878 & 1.280 & - \\
\hline & Control & 103 & 2.533 & 3.267 & 1.460 & 0.001 & 17.472 & 1.894 & 3.171 & - \\
\hline & Difference & - & -1.454 & - & - & - & - & -2.122 & -0.786 & $<0.001$ \\
\hline
\end{tabular}

Abbreviation: IOL, intraocular lens; Max, maximum; Min, minimum.

Table 5 Comparisons of Mean Absolute IOL Rotations for Version I versus Version 2 at Postoperative Day I, Week I, Month I, and Month 6

\begin{tabular}{|c|c|c|c|c|c|c|c|c|c|c|}
\hline $\begin{array}{l}\text { Postoperative Time } \\
\text { Point }\end{array}$ & IOL & $\mathbf{N}$ & $\begin{array}{c}\text { Mean } \\
\text { Degrees }\end{array}$ & SD & Median & Min & Max & $\begin{array}{c}\text { Lower } 95 \% \\
\mathrm{Cl}\end{array}$ & $\begin{array}{c}\text { Upper } 95 \% \\
\mathrm{Cl}\end{array}$ & $P$ \\
\hline \multirow[t]{3}{*}{ Day I } & Version I & 92 & $0.84 I$ & 0.994 & 0.517 & 0.012 & 4.745 & 0.636 & 1.047 & - \\
\hline & Version 2 & 89 & 0.727 & 0.753 & 0.448 & 0.001 & 3.298 & 0.568 & 0.885 & - \\
\hline & Difference & 87 & 0.082 & - & - & - & - & -0.175 & 0.339 & 0.5260 \\
\hline \multirow[t]{3}{*}{ Week I } & Version I & 93 & 0.877 & 0.939 & 0.654 & 0.016 & 4.719 & 0.684 & 1.070 & - \\
\hline & Version 2 & 91 & 0.713 & 0.690 & 0.460 & 0.006 & 2.742 & 0.569 & 0.856 & - \\
\hline & Difference & 89 & 0.170 & - & - & - & - & -0.045 & 0.385 & 0.1240 \\
\hline \multirow[t]{3}{*}{ Month I } & Version I & 91 & 0.989 & 0.953 & 0.791 & 0.004 & 5.517 & 0.790 & 1.187 & - \\
\hline & Version 2 & 86 & 0.871 & 0.915 & 0.537 & 0.010 & 6.166 & 0.675 & 1.067 & - \\
\hline & Difference & 84 & 0.080 & - & - & - & - & -0.164 & 0.323 & 0.5164 \\
\hline \multirow[t]{3}{*}{ Month 6} & Version I & 92 & 1.079 & 0.972 & 0.821 & 0.023 & 4.633 & 0.878 & 1.280 & - \\
\hline & Version 2 & 86 & 1.031 & 1.094 & 0.692 & 0.027 & 6.354 & 0.796 & 1.266 & - \\
\hline & Difference & 84 & 0.040 & - & - & - & - & -0.239 & 0.319 & 0.7766 \\
\hline
\end{tabular}

Abbreviation: IOL, intraocular lens.

current TECNIS toric IOL (Table 1). In the case of the first test IOL (version 1), the haptic shape was also modified such that the overall diameter of the IOL was $0.5 \mathrm{~mm}$ larger than that of the current TECNIS toric (ZCT series) design. For the second test IOL (version 2), the haptic geometry and diameter were the same as those of the current TECNIS toric IOL (ie, the only difference between version 2 and the control IOLs was the frosted and squared haptics). This suggests that the significant reduction in postoperative IOL rotation observed with both the version 1 and version 2 IOLs in this study was the result of greater static friction between the frosted haptic arms and the capsular bag. The lack of statistically significant difference in absolute rotation between the version 1 and version 2 designs suggested that frosting and squaring the haptics were the most significant design factors in improving rotational stability, and the additional design changes for version 1 (larger overall diameter and modified haptic geometry) provided no additional benefit.

Both test IOLs were found to have significantly lower mean absolute rotation at the postoperative week 1 time point compared with the control IOL, and this trend in 


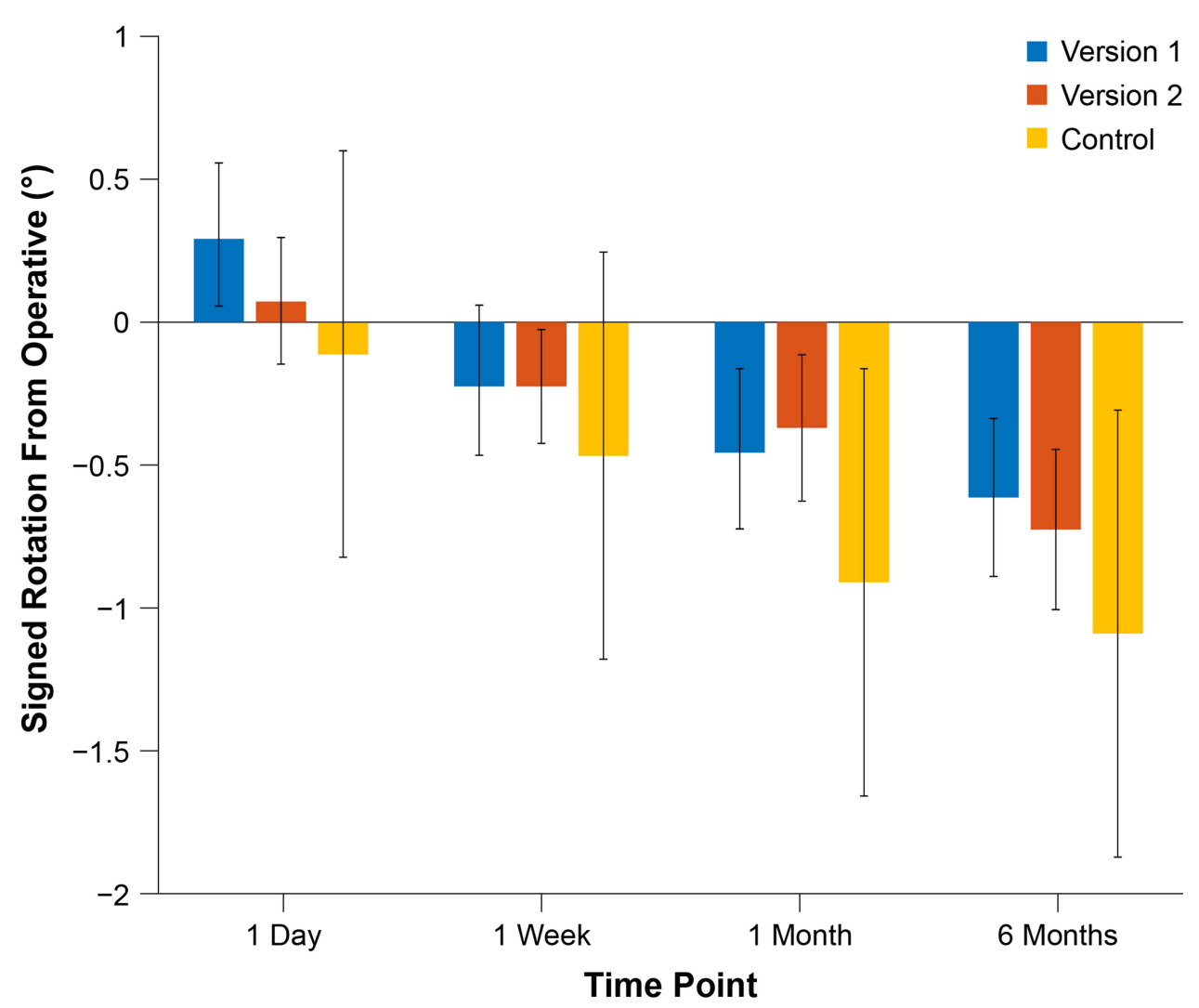

Figure 4 Mean signed IOL rotation from operative to postoperative day I, week I, month I, and month 6 for the version I, version 2, and control IOLs. Negative values indicate clockwise rotation, as observed from a slit lamp. Error bars represent $95 \% \mathrm{Cls}$ of the mean values.

Abbreviation: IOL, intraocular lens.

favor of the test lenses was maintained at the postoperative month 1 and month 6 time points for both version 1 and version 2. The mean absolute rotation for both test IOLs tended to be lower than previously reported for the TECNIS toric IOL $\left(1^{\circ}\right.$ to $\left.5^{\circ}\right),{ }^{7,8,10}$ the AcrySof toric IOL (Alcon Laboratories, Inc., Fort Worth, TX, USA) $\left(1.5^{\circ}\right.$ to $\left.4.5^{\circ}\right){ }^{7,11,12}$ and the enVista Toric IOL (Bausch+Lomb, Inc. Rochester, NY, USA) $\left(1.11^{\circ}\right) .^{13}$ Additionally, no cases of lens rotation $>5^{\circ}$ were observed for either test IOL through 1 week of postoperative follow-up in this study; mean absolute rotation was low at both the postoperative day 1 $\left(0.84^{\circ}\right.$ and $\left.0.73^{\circ}\right)$ and week $1\left(0.88^{\circ}\right.$ and $\left.0.71^{\circ}\right)$ time points, respectively. For both test IOLs, no more than one eye was found to have absolute rotation $>5^{\circ}$ at either the postoperative month 1 or month 6 time points - that is, at least $98.8 \%$ of eyes had absolute rotation of $<5^{\circ}$ from 1 month onward, indicating that both test IOLs provided acceptable long-term rotational stability. Previous studies that have investigated a range of toric IOL designs have reported comparable findings. ${ }^{3,8,12,14,15}$ In a study evaluating four TECNIS Toric IOLs from the ZCT series (ZCT150, ZCT225, ZCT300, and ZCT400), pooled data for all four lenses demonstrated a mean absolute rotation of $2.70^{\circ}\left( \pm 5.51^{\circ}\right)$ between postoperative day 1 and month $6 .{ }^{15}$ It is important to note that in that study, baseline photographs for rotational analysis were captured at postoperative day 1 , whereas in the present study, baseline photographs were captured during the operative visit immediately before the participant was discharged from the operating room. Using the operative photograph as a baseline, the signed rotation at postoperative day 1 was highly correlated with the signed rotation at future time points for both test and control lenses in this study, suggesting that most lens rotation occurred before the postoperative day 1 visit. This finding is in agreement with results published by Inoue et $\mathrm{al}^{8}{ }^{8}$ in which IOL rotation was greatest within 1 hour following surgery for the TECNIS toric IOL. It is also congruent with the results of a study by Schartmüller et $\mathrm{al}^{3}{ }^{3}$ in which rotation of the Vivinex XY1 IOL (Hoya Corporation, Tokyo, Japan) was significantly greater within the first hour following implantation than at later time points. ${ }^{3}$ Similar results have been published by Miyake et $\mathrm{al}^{12}$ for the AcrySof (Alcon) toric IOL, in which IOL rotation was analyzed from 1 day to 2 

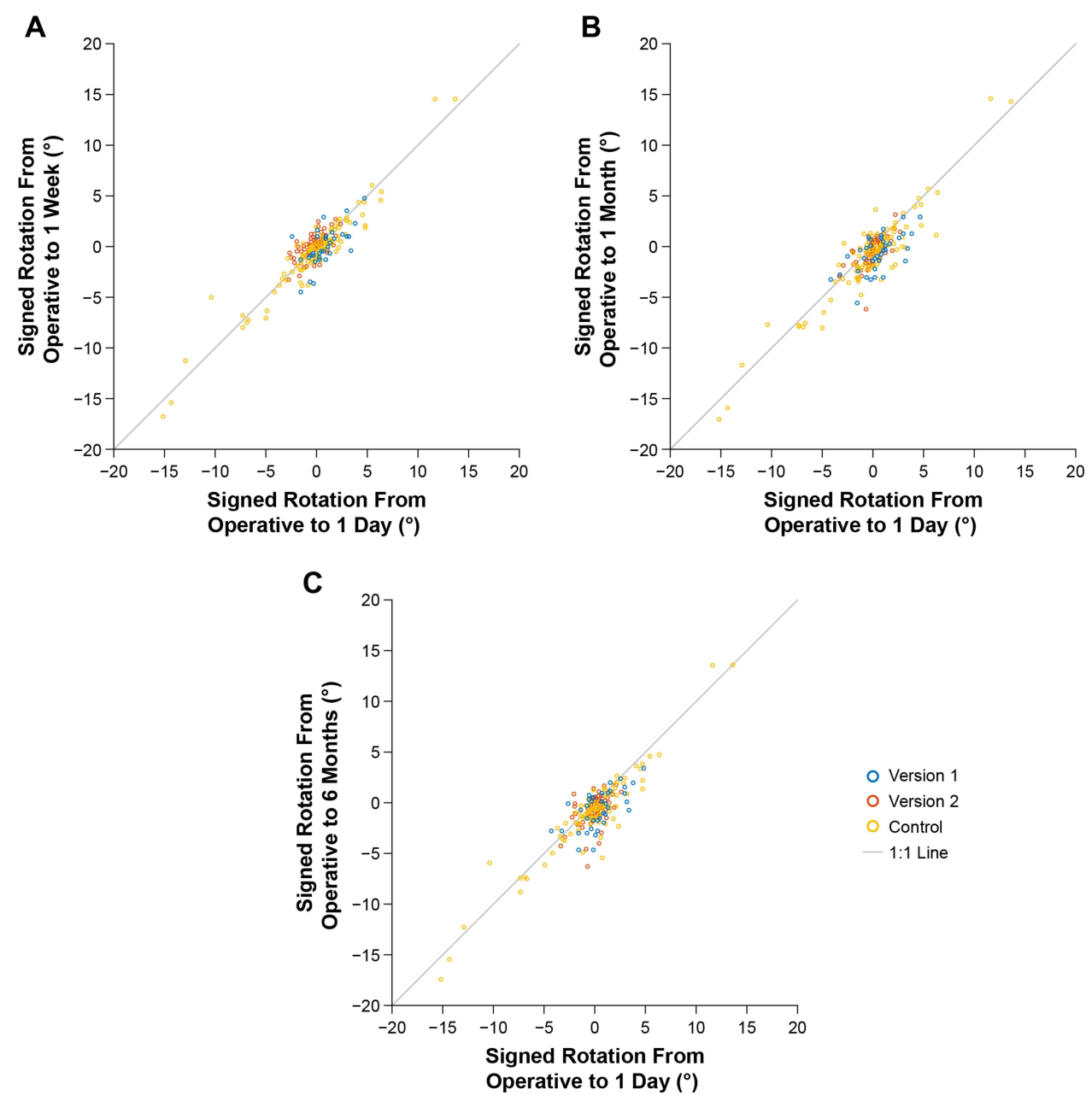

Figure 5 Scatterplots of signed IOL rotation at postoperative day I versus week I (A), postoperative day I versus month I (B), and postoperative day I versus month 6 (C). Abbreviation: IOL, intraocular lens.

years postoperatively, and it was found that the greatest IOL rotation occurred within 1 day following surgery.

In the current study, one case of lens rotation $>5^{\circ}$ was reported for both the version 1 and version 2 IOLs. For version 2 , the absolute rotation was $6.2^{\circ}$ at 1 month, which was double the next highest amount of lens rotation reported at this time point for this lens $\left(3.1^{\circ}\right)$. At 6 months, absolute rotation for this participant remained stable at $6.4^{\circ}$. The investigator noted that this lens was not well situated within the capsular bag, with the superior edge of the IOL reported to be sitting in front of the anterior capsule at a postoperative visit; thus, the rotation observed in this case might have resulted from the nonstandard positioning of the IOL. For the version 1 case with rotation $>5^{\circ}$ at 1 month, the absolute rotation was $4.6^{\circ}$ at 1 week, $5.5^{\circ}$ at 1 month, and $4.6^{\circ}$ at 6 months, suggesting that this 1-month datapoint was the result of stochastic noise inherent to the photographic analysis method.

A small but statistically significant clockwise bias in the direction of lens rotation was observed at the postoperative week 1 time point for the version 2 lens and at the postoperative month 1 and month 6 time points for both test lenses and the control lens. These findings are in contrast to previous reports suggesting a counterclockwise bias for the TECNIS toric IOL. ${ }^{6,7}$ However, the mean signed rotation for all models at all time points was small; the largest mean signed rotation was $-1.1^{\circ}$ at 6 months for the control lens and was thus not considered clinically significant.

In a previous case series assessing the rotational stability of the AcrySof toric IOL in 168 eyes by Shah et al, ${ }^{11}$ a strong positive correlation was found between 


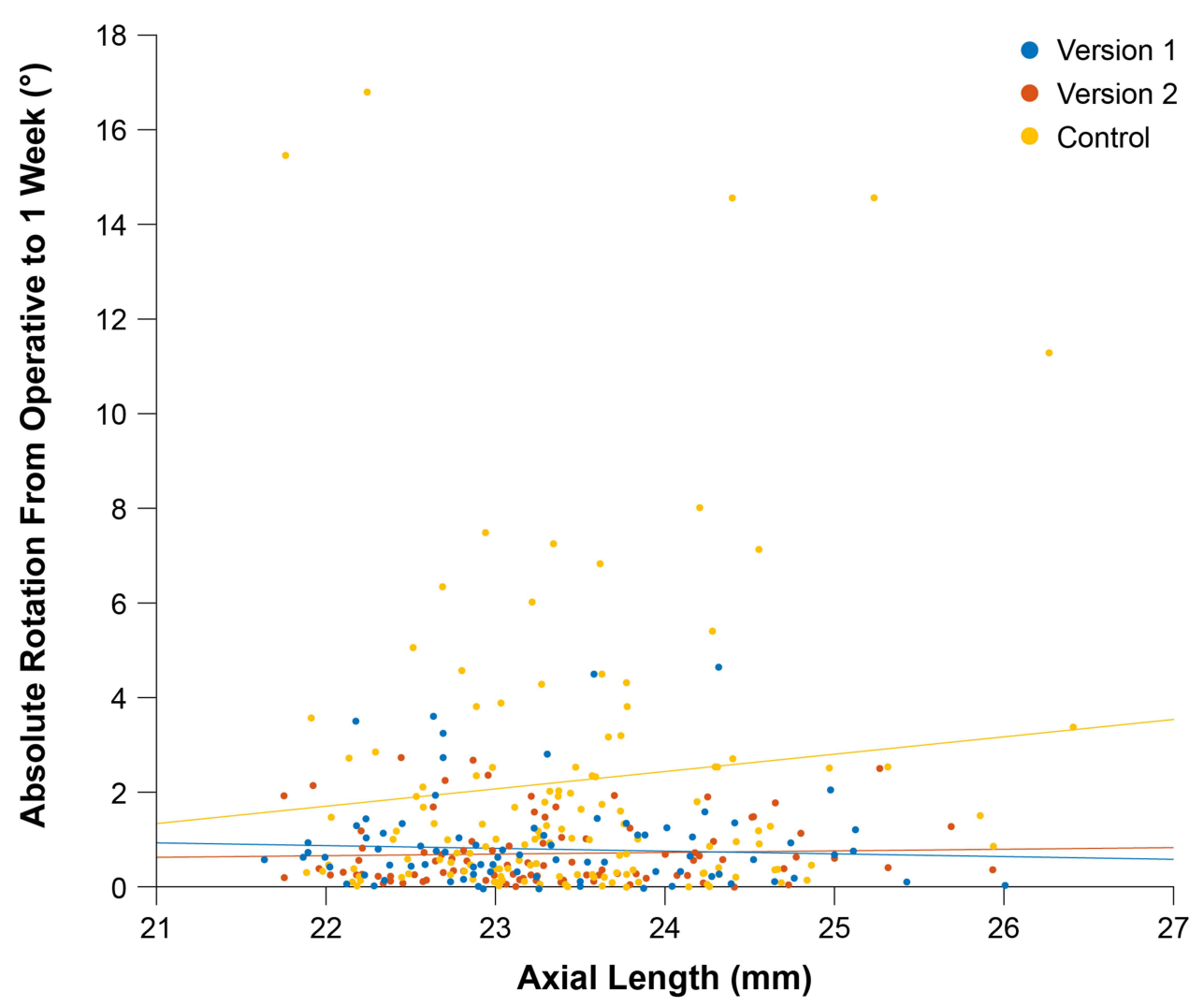

Figure 6 Scatterplot of absolute IOL rotation at postoperative week I versus axial length for the version I, version 2, and control IOLs. Abbreviation: IOL, intraocular lens.

absolute IOL rotation and axial length $(r=0.93$ $P<0.001$ ), that is, toric IOL rotation tended to be greater in eyes with longer axial length. ${ }^{11}$ As shown in Figure 5, data for the control lens in this study follow the same trend; however, linear regression indicated that this correlation was not statistically significant, nor was any significant correlation evident for either of the test lenses. The range of axial lengths of eyes in this study (range, 21.8-26.4 $\mathrm{mm}$ ) was considerably smaller than that evaluated by Shah et al ${ }^{11}$ (range, 19.5-29.0 mm); thus, the lack of significance in this study may have been the result of a smaller effect size.

Surgeon responses to the postoperative questionnaire suggest that the version 2 design offered slightly greater resistance to positioning in both clockwise and counterclockwise directions, whereas the responses to these questions for the version 1 IOL were more similar to those for the control IOLs. The responses also suggested that both test lenses were less likely to be impacted by the removal of viscoelastic from behind the lens than the control lens. Collectively, the questionnaire and rotation data for these IOLs suggest a balance between rotational stability and ease of rotation during surgery-ie, that greater resistance to positioning during surgery may be correlated to better postoperative stability.

This study was conducted at three sites in Asia Pacific and Latin America, resulting in a predominantly Asian or "other" race participant population. Although this may limit the generalizability of the results of this study, to our knowledge there is no empirical evidence in the literature of racial or ethnic differences having an impact on rotational stability as a function of differences in ocular anatomy. Therefore, the results of this study are thought to be generalizable to other populations. Although data for the control IOL were obtained from a separate trial, the demographics of participants were comparable for both trials. Additionally, the surgeons who participated in this study were a subset of those in the investigation of the control lens; thus, any effect of variability in participantrelated or site-related factors on outcomes was likely to be small. 
A

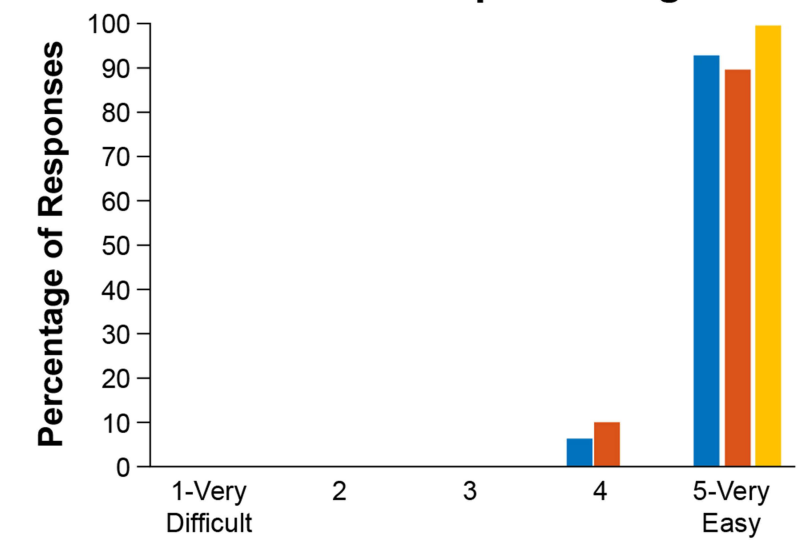

C Positioning the IOL Counterclockwise at the Correct Axis

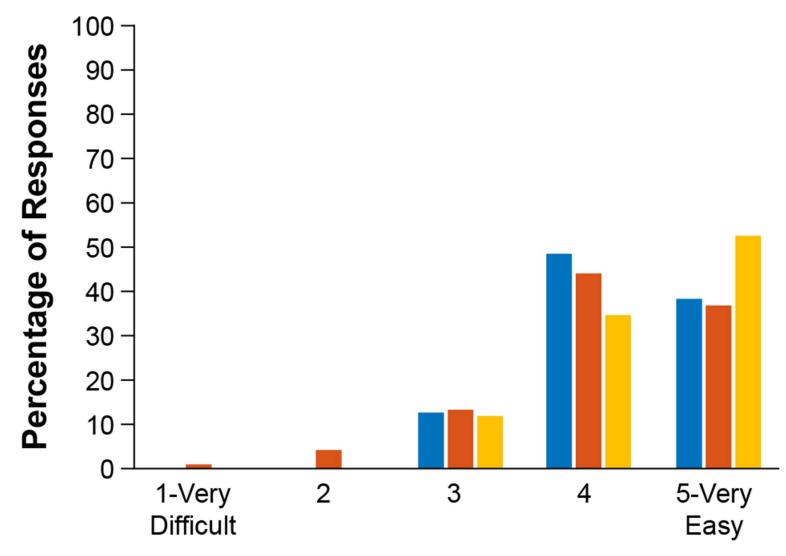

B
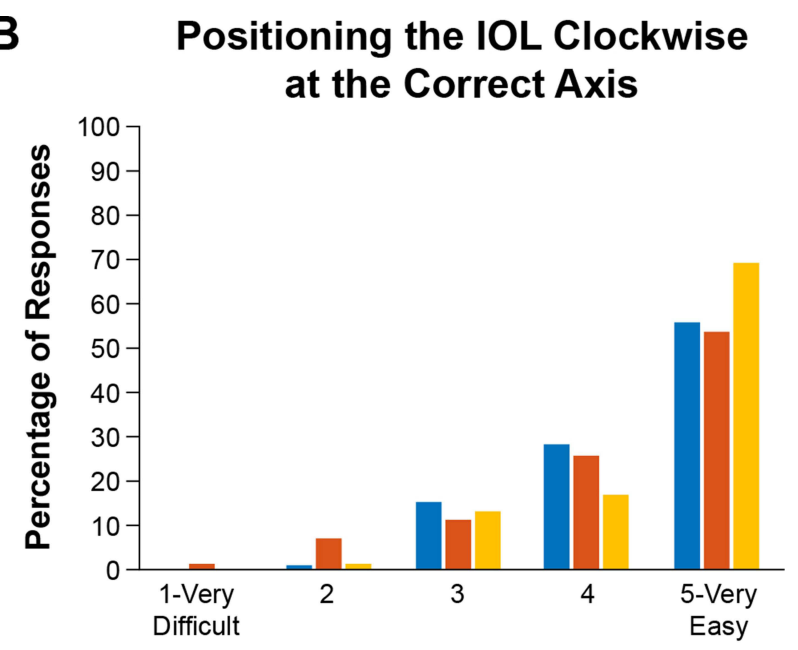

D
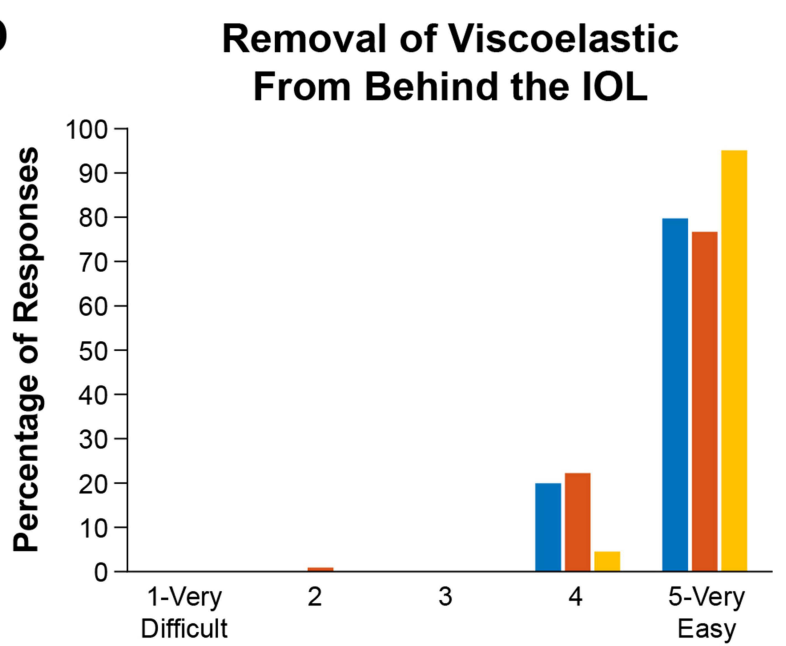

E Lens Position Impacted by the Removal of Viscoelastic From Behind the IOL

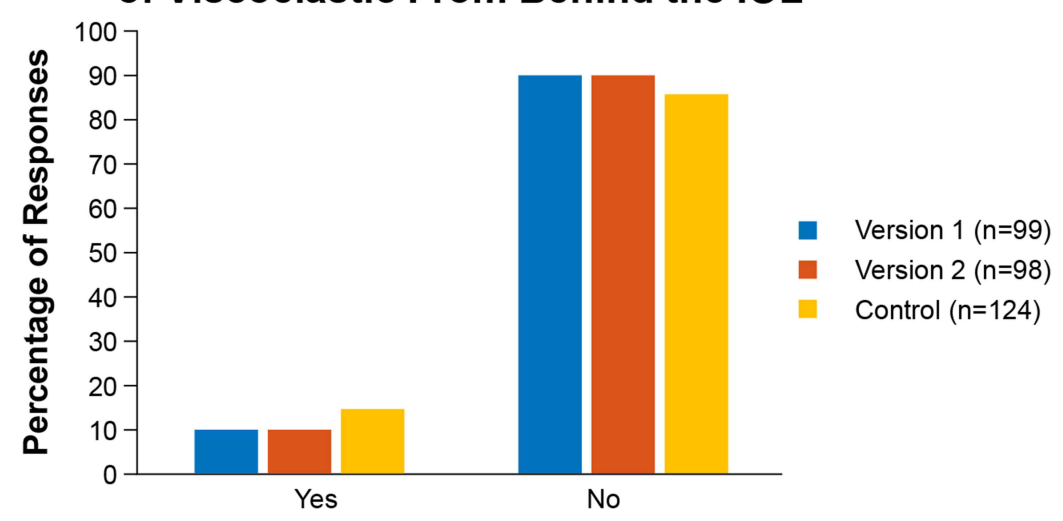

Figure 7 Surgeon responses to the operative questionnaire on ease of IOL handling during implantation for the version I, version 2, and control IOLs. The operative questionnaire comprised questions on the following: ease of implantation of the IOL into the capsular bag (A); ease of positioning the IOL clockwise at the correct axis (B); ease of positioning the IOL counterclockwise at the correct axis (C); ease of removal of viscoelastic from behind the IOL (D); and whether or not the lens position was impacted by the removal of viscoelastic from behind the IOL (E).

Abbreviation: IOL, intraocular lens. 


\section{Conclusions}

In conclusion, both test IOLs evaluated in this study demonstrated a significant improvement in rotational stability compared with a control IOL at all postoperative visits up to 6 months. Both test IOLs stabilized within 1 day of implantation, and rotational stability was maintained at all follow-up visits. All eyes implanted with test lenses had $<5^{\circ}$ rotation at 1 week, and no rotations $>10^{\circ}$ were observed with either test IOL through postoperative month 6. Although both test lenses showed improvement over the control IOL and the difference between them was not statistically significant, the consistently lower mean absolute rotation for version 2 suggests it may trend towards greater stability than version 1. Given these results, and in consideration of version 2 having an overall haptic geometry identical to that of the current TECNIS toric IOL, this design was selected for commercialization under the brand name TECNIS Toric II (Johnson \& Johnson Vision).

\section{Abbreviations}

$\mathrm{AE}$, adverse event; IOL, intraocular lens; Min, minimum; Max, maximum; SAE, serious adverse event; SD, standard deviation.

\section{Data Sharing Statement}

The authors do not intend to share individual deidentified participant data. A summarized report with end point data tables based on statistical plan and analysis may be requested directly from the corresponding author for consideration. Access to anonymized data may be granted following review. Content with granted access will be available through email or other appropriate formats and for 3 months, upon review and consideration.

\section{Ethics and Consent Statement}

Human participants were included in this study. The IRB/ ethics committee of each participating study site approved this study. All research was conducted in accordance with the Declaration of Helsinki. All participants provided signed informed consent.

\section{Acknowledgments}

Manuscript development and editorial support was provided by ApotheCom (Yardley, PA) and funded by Johnson \& Johnson Surgical Vision, Inc. The following surgeons participated in this clinical program: Robert E. Ang, MD (Asian Eye
Institute, Manila, Philippines); Kevin L. Waltz, MD, Rodrigo Quesada, MD, Gabriel Quesada, MD, and John A. Vukich, MD (Clinica Quesada, Centro de Oftalmología y Cirugía Plástica, San Salvador, El Salvador); and Juan F. Batlle, MD, and Rafael Feliz, MD (Laser Center, Santo Domingo, Dominican Republic). Interim data presented at American Academy of Ophthalmology Annual Meeting, October 12 15, 2019, San Francisco, California (oral), and American Society of Cataract and Refractive Surgery Virtual Annual Meeting, May 16-17, 2020 (oral); pooled data from this study and other trials presented at Association for Research in Vision and Ophthalmology Annual Meeting, May 3-7, 2020, Baltimore, Maryland, USA (oral presentation).

\section{Author Contributions}

All authors made a significant contribution to the work reported, whether that is in the conception, study design, execution, acquisition of data, analysis and interpretation, or in all these areas; took part in drafting, revising, or critically reviewing the article; gave final approval of the version to be published; have agreed on the journal to which the article has been submitted; and agreed to be accountable for all aspects of the work.

\section{Funding}

This study was supported by Johnson \& Johnson Surgical Vision, Inc., which participated in the design and conduct of the study.

\section{Disclosure}

The authors have made the following disclosures:

J. A. V.: Personal fees and nonfinancial support from Johnson \& Johnson Surgical Vision during the conduct of the study; grants and personal fees from Johnson \& Johnson Surgical Vision outside the submitted work. R. E. A.: Grants from Johnson \& Johnson Surgical Vision during the conduct of the study. B. J. K. S.: Personal fees and nonfinancial support from Johnson \& Johnson Surgical Vision during the conduct of the study; personal fees, nonfinancial support, and other (owns shares) from Johnson \& Johnson Surgical Vision outside the submitted work. D. P. J.: Employee of Johnson \& Johnson Surgical Vision at the time of manuscript preparation. P. J. S.: Personal fees from Johnson \& Johnson Surgical Vision during the conduct of the study. J. F. B.: Grants and personal fees from Johnson \& Johnson Surgical Vision outside the submitted work. K. L. W.: Honoraria from and research services for Johnson \& Johnson Surgical Vision during the conduct of the study; personal fees from and 
research support and/or consulting relationship with Alcon, BVI, Johnson \& Johnson, Rayner, Bausch Health, and Zeiss, outside the submitted work.

\section{References}

1. Kessel L, Andresen J, Tendal B, Erngaard D, Flesner P, Hjortdal J. Toric intraocular lenses in the correction of astigmatism during cataract surgery: a systematic review and meta-analysis. Ophthalmology. 2016;12:275-286.

2. Ma JJ, Tseng SS. Simple method for accurate alignment in toric phakic and aphakic intraocular lens implantation. $J$ Cataract Refract Surg. 2008;34:1631-1636. doi:10.1016/j.jcrs.2008.04.041

3. Schartmuller D, Schriefl S, Schwarzenbacher L, Leydolt C, Menapace R. True rotational stability of a single-piece hydrophobic intraocular lens. Br J Ophthalmol. 2019;103(2):186-190. doi:10.11 36/bjophthalmol-2017-311797

4. Hahn U, Krummenauer F, Schmickler S, Koch J. Rotation of a toric intraocular lens with and without capsular tension ring: data from a multicenter non-inferiority randomized clinical trial (RCT). BMC Ophthalmol. 2019;19:143. doi:10.1186/s12886-019-1147-5

5. The TECNIS ${ }^{\circledR}$ Toric 1-Piece (IOL). Santa Ana, CA: Johnson \& Johnson Vision, Inc; 2020. Available from: https://www.precisionlens.net/wpcontent/uploads/JJ-Tecnis-Toric-DFU.pdf. Accessed June 29, 2020.

6. Potvin R, Kramer BA, Hardten DR, Berdahl JP. Toric intraocular lens orientation and residual refractive astigmatism: an analysis. Clin Ophthalmol. 2016;10:1829-1836. doi:10.2147/OPTH.S114118

7. Lee BS, Chang DF. Comparison of the rotational stability of two toric intraocular lenses in 1273 consecutive eyes. Ophthalmology. 2018; 125:1325-1331. doi:10.1016/j.ophtha.2018.02.012
8. Inoue Y, Takehara H, Oshika T. Axis misalignment of toric intraocular lens: placement error and postoperative rotation. Ophthalmology. 2017;124:1424-1425. doi:10.1016/j.ophtha.20 17.05.025

9. Kasthurirangan S, Feuchter L, Smith P, Nixon D. Software-based evaluation of toric IOL orientation in a multicenter clinical study. J Refract Surg. 2014;30:820-826. doi:10.3928/1081597X-20141117-01

10. Lubinski W, Kazmierczak B, Gronkowska-Serafin J, Podboraczynska-Jodko K. Clinical outcomes after uncomplicated cataract surgery with implantation of the Tecnis toric intraocular lens. J Ophthalmol. 2016;2016:3257217. doi:10.1155/2016/3257217

11. Shah GD, Praveen MR, Vasavada AR, Vasavada VA, Rampal G, Shastry LR. Rotational stability of a toric intraocular lens: influence of axial length and alignment in the capsular bag. $J$ Cataract Refract Surg. 2012;38(1):54-59. doi:10.1016/j.jcrs.2011.08.028

12. Miyake T, Kamiya K, Amano R, Iida Y, Tsunehiro S, Shimizu K. Long-term clinical outcomes of toric intraocular lens implantation in cataract cases with preexisting astigmatism. $J$ Cataract Refract Surg. 2014;40:1654-1660. doi:10.1016/j.jcrs.2014.01.044

13. Packer M, Williams JI, Feinerman G, Hope RS. Prospective multicenter clinical trial to evaluate the safety and effectiveness of a new glistening-free one-piece acrylic toric intraocular lens. Clin Ophthalmol. 2018;12:1031-1039. doi:10.2147/OPTH.S167726

14. Bachernegg A, Ruckl T, Riha W, Grabner G, Dexl AK. Rotational stability and visual outcome after implantation of a new toric intraocular lens for the correction of corneal astigmatism during cataract surgery. $J$ Cataract Refract Surg. 2013;39(9):1390-1398. doi:10.10 16/j.jcrs.2013.03.033

15. Waltz KL, Featherstone K, Tsai L, Trentacost D. Clinical outcomes of Tecnis toric intraocular lens implantation after cataract removal in patients with corneal astigmatism. Ophthalmology. 2015;122:39-47. doi:10.1016/j.ophtha.2014.06.027
Clinical Ophthalmology

\section{Publish your work in this journal}

Clinical Ophthalmology is an international, peer-reviewed journal covering all subspecialties within ophthalmology. Key topics include: Optometry; Visual science; Pharmacology and drug therapy in eye diseases; Basic Sciences; Primary and Secondary eye care; Patient Safety and Quality of Care Improvements. This journal is indexed on PubMed

\section{Dovepress}

Central and CAS, and is the official journal of The Society of Clinical Ophthalmology (SCO). The manuscript management system is completely online and includes a very quick and fair peer-review system, which is all easy to use. Visit http://www.dovepress.com/ testimonials.php to read real quotes from published authors. 